\title{
Cobalamin Inactivation Decreases Purine and Methionine Synthesis in Cultured Lymphoblasts
}

\author{
Gerry R. Boss \\ Department of Medicine, University of California, San Diego Medical Center, San Diego, California 92103
}

\begin{abstract}
The megaloblastic anemia of cobalamin deficiency appears secondary to decreased methionine synthetase activity. Decreased activity of this enzyme should cause 5-methyltetrahydrofolate to accumulate intracellularly, and consequently, decrease purine and DNA synthesis; this is the basis of the "methylfolate trap" hypothesis of cobalamin deficiency. However, only some of the clinical and biochemical manifestations of cobalamin deficiency can be explained by the methylfolate trap. We investigated cobalamin deficiency by treating cultured human lymphoblasts with $\mathrm{N}_{2} \mathrm{O}$ since $\mathrm{N}_{2} \mathrm{O}$ inhibits methionine synthetase activity by inactivating cobalamin. We found that 4 $h$ of $\mathrm{N}_{2} \mathrm{O}$ exposure reduced rates of methionine synthesis by $89 \%$. Rates of purine synthesis werè not significantly reduced by $\mathrm{N}_{2} \mathrm{O}$ when folate and methionine were present at $100 \mu \mathrm{M}$ in the medium; however, at the physiologic methionine concentration of $10 \mu \mathrm{M}, \mathrm{N}_{2} \mathrm{O}$ decreased rates of purine synthesis by 33 and $57 \%$ in the presence of $100 \mu \mathrm{M}$ folate and in the absence of folate, respectively. The dependency of rates of purine synthesis on methionine availability would be expected in cells with restricted methionine synthetic capacity because (a) methionine is the immediate precursor of $S$-adenosylmethionine, a potent inhibitor of 5-methyltetrahydrofolate synthesis; (b) methionine serves as a source of formate for purine synthesis; and (c) rates of purine synthesis are dependent on the intracellular availability of essential amino acids. We conclude that cobalamin inactivation decreases purine synthesis by both methylfolate trapping and reduction of intracellular methionine synthesis.
\end{abstract}

\section{Introduction}

In animals only two enzymes are known to require cobalamin (vitamin $\left.\mathrm{B}_{12}\right)$ as a coenzyme, methionine synthetase $\left(N^{5}\right.$ methyltetrahydrofolate-homocysteine methyltransferase, EC 2.1.1.13) and methylmalonyl coenzyme A mutase (EC 5.4.99.2) (1). Cobalamin deficiency leads to megaloblastic anemia, which appears secondary to decreased methionine synthetase activity, and to subacute combined degeneration of the spinal cord, which may be secondary to decreased methylmalonyl CoA mutase activity $(2,3)$. A decrease in methionine synthetase activity would be expected to cause 5-methyltetrahydrofolate

Address reprint requests to Dr. Boss at Department of Medicine, H-811H, University of California, San Diego Medical Center, 225 Dickinson St., San Diego, CA 92103.

Received for publication 14 January 1985.

J. Clin. Invest.

(c) The American Society for Clinical Investigation, Inc.

$0021-9738 / 85 / 07 / 0213 / 06 \$ 1.00$

Volume 76, July 1985, 213-218 to accumulate at the expense of other forms of folate because (a) 5-methyltetrahydrofolate appears to be the major storage form of intracellular folates (4), and (b) the conversion of 5,10methylene tetrahydrofolate to 5-methyltetrahydrofolate by 5,10 methylene tetrahydrofolate reductase (EC 1.1.1.68), although fully reversible in vitro, may be irreversible in vivo (Fig. 1) (5). These data form the basis of the "methylfolate trap" hypothesis of cobalamin deficiency $(6,7)$. Trapping folates as 5-methyltetrahydrofolate should lead to decreased purine, thymidylate, and $S$-adenosylmethionine synthesis (Fig. 1); and thus, to decreased DNA synthesis and methylation; and ultimately, to megaloblastosis. Support for the methylfolate trap hypothesis is that the megaloblastosis of cobalamin deficiency responds to large doses of folate (8). However, physiologic doses of folate capable of producing a maximal response in folate deficiency produce only a partial or no response in cobalamin deficiency (9-10). Moreover, animal studies only partially support methylfolate trapping in cobalamin deficiency $(11,12)$.

Nitrous oxide $\left(\mathrm{N}_{2} \mathrm{O}\right)$ induces megaloblastic changes in bone marrow cells within $6 \mathrm{~h}$ when used as an anesthetic and has caused fatal megaloblastic anemia when used in the treatment of tetanus $(13,14)$. In rats, $\mathrm{N}_{2} \mathrm{O}$ rapidly inhibits methionine synthetase activity by oxidizing the active cobalamin $\mathrm{I}$ to the inactive cobalamin III (15). $\mathrm{N}_{2} \mathrm{O}$ may be used, therefore, to create a model of cobalamin deficiency $(15,16)$.

To determine the sequelae of cobalamin inactivation, we measured the following parameters in $\mathrm{N}_{2} \mathrm{O}$-treated cultured human lymphoblasts: $(a)$ ratès of methionine and serine synthesis; $(b)$ rates of purine synthesis at variable folate concentration; $(c)$ rates of purine synthesis at variable methionine concentration; and $(d)$ rates of purine synthesis in the presence of homocysteine. We found that $\mathrm{N}_{2} \mathrm{O}$ decreased rates of purine synthesis and this decrease was attributable to both methylfolate trapping and decreased methionine synthesis.

\section{Methods}

The B lymphoblast line MGL8B2 was established in the Genetics Unit of the Massachusetts General Hospital, Boston, MA, by Epstein-Barr virus transformation of peripheral blood lymphocytes from a normal donor. The cells were routinely cultured as previously described (17).

Preparation of methionine-deficient or folate-deficient medium. The methionine-deficient medium was prepared as previously described (17) and supplemented to $1.5 \mu \mathrm{M}$ cobalamin. The folate-deficient medium was prepared similarly, replacing the modified Eagle's medium vitamin solution with $11 \mu \mathrm{M}$ myoinositol, $8 \mu \mathrm{M}$ nicotinamide, $4 \mu \mathrm{M}$ pantothenic acid, $5 \mu \mathrm{M}$ pyridoxine, $0.25 \mu \mathrm{M}$ riboflavin, and $3 \mu \mathrm{M}$ thiamine. Both media were serum-free and contained $5 \mathrm{~g} /$ liter of extensively dialyzed fatty acid-free bovine serum albumin (no. A7030, Sigma Chemical Co., St. Louis, MO).

Exposure of cells to $\mathrm{N}_{2} \mathrm{O}$. Cells were recovered by centrifugation from the growth medium and resuspended at a density of $1.5 \times 10^{6} \%$ $\mathrm{ml}$ in the experimental medium. The cell suspension was transferred to $16 \times 100$-mm glass tubes which were flushed with either $95 \%$ air/ 


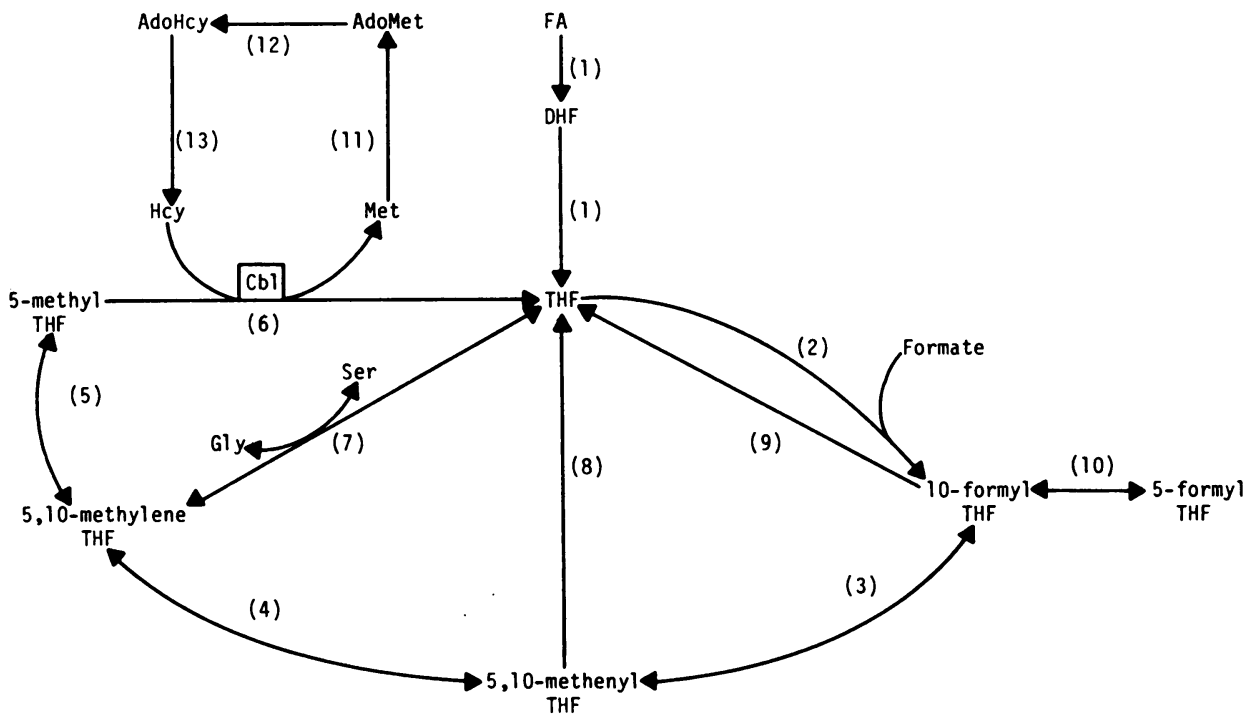

Figure 1. Folate and cobalamin reactions involved in methionine and purine synthesis. Enzymes: (1) dihydrofolate reductase; (2) 10-formyl tetrahydrofolate (THF) synthetase; (3) 5,10methenyl THF cyclohydrolase; (4) 5,10-methylene THF dehydrogenase; (5) 5,10-methylene THF reductase; (6) methionine synthetase; (7) serine transhydroxymethylase; (8) glycineamide transformylase; (9) aminoimidazole carboxamide transformylase; (10) formyl THF isomerase; (11) methionine adenosyltransferase; (12) methyltransferase reactions; and (13) S-ädenosylhomocysteine hydrolase. FA, folic acid (pteroylglutamic acid); DHF, dihydrofolate; Gly, glycine; Ser, serine; Cbl, cobalamin; Met, methionine; AdoMet, $S$-adenosylmethionine; AdoHcy, $S$-adenosylhomocysteine; and Hcy, homocysteine. Enzymes 2, and two of the purine ring, respectively.

$5 \% \mathrm{CO}_{2}$ or $75 \% \mathrm{~N}_{2} \mathrm{O} / 20 \% \mathrm{O}_{2} / 5 \% \mathrm{CO}_{2}$, tightly capped and incubated at $37^{\circ} \mathrm{C}$ in a shaking water bath. In preliminary experiments we found that cell viability, as measured by trypan blue exclusion, exceeded $90 \%$ after $18 \mathrm{~h}$ under both the control and $\mathrm{N}_{2} \mathrm{O}$-treated conditions.

Measurement of methionine and serine synthesis. Rates of methionine and serine synthesis were measured as previously described (18, 19). Briefly, $20 \mu \mathrm{Ci}$ of $\left[{ }^{14} \mathrm{C}\right]$ formate $(42 \mathrm{mCi} / \mathrm{mmol}$, ICN Pharmaceuticals, Irvine, CA) were added to $2 \mathrm{ml}$ of cell suspension; after $2 \mathrm{~h}$ the tubes were cooled on ice, centrifuged at $500 \mathrm{~g}$ for $5 \mathrm{~min}$, and the medium discarded. The cell pellet was extracted in 5\% TCA for 30 min, heated at $80^{\circ} \mathrm{C}$ for $30 \mathrm{~min}$, and then, cooled on ice for $30 \mathrm{~min}$. The resulting protein precipitate, free of nucleic acids, was washed three times in ice-cold 10\% TCA and resuspended in ultrapure $6 \mathrm{~N}$ $\mathrm{HCl}$. After $20 \mathrm{~h}$ of hydrolysis at $110^{\circ} \mathrm{C}$, the $\mathrm{HCl}$ was evaporated under vacuum at $70^{\circ} \mathrm{C}$ and the hydrolysate was resuspended in $\mathrm{H}_{2} \mathrm{O}$. Methionine and its oxidation productions, methionine sulfoxide and methionine sulfone, were separated from serine and cysteine and its oxidation products, cystine and cysteic acid, in a phenol/ethanol/ $\mathrm{H}_{2} \mathrm{O}$ / $\mathrm{NH}_{4} \mathrm{OH}(65: 20: 20: 2)$ one-dimensional solvent system on cellulose thinlayer chromatography sheets. Nonradioactive marker amino acids were visualized under ultraviolet light after the plates were dipped in a $0.01 \%$ fluorescamine acetone solution. The appropriate spots were cut out of the chromatograph and counted at $\sim 95 \%$ efficiency. Since serine condenses with homocysteine to yield cystathionine, which is converted to cysteine, radioactivity in cysteine originates from the serine and is thus included as part of serine. The assay measures newly synthesized methionine or serine incorporated into cellular protein; the data are expressed as picomoles of $\left[{ }^{14} \mathrm{C}\right]$ formate incorporated into methionine or serine per hour per $10^{6}$ cells. The assay was linear with time to at least $4 \mathrm{~h}$ and with cell density from 0.5 to $2 \times 10^{6}$ cells $/ \mathrm{ml}$.

Measurement of rates of de novo purine synthesis. Rates of de novo purine synthesis were measured as previously described (17). Briefly, $10 \mu \mathrm{Ci}$ of $\left[{ }^{14} \mathrm{C}\right]$ formate were added to $1 \mathrm{ml}$ of cell suspension for $1 \mathrm{~h}$. The tubes were cooled on ice, and cells and media were extracted separately in $0.4 \mathrm{~N}$ perchloric acid. After heating at $100^{\circ} \mathrm{C}$ for $70 \mathrm{~min}$ to hydrolyze the ribose-purine bond, the tubes were centrifuged and the supernatants were applied to Dowex-50 cation exchange columns. The columns were washed twice with $10 \mathrm{ml}$ of $0.1 \mathrm{~N} \mathrm{HCl}$ and the purines were eluted in $5 \mathrm{ml}$ of $6 \mathrm{~N} \mathrm{HCl}$ of which $1 \mathrm{ml}$ was used to measure radioactivity at $\sim 90 \%$ efficiency. Total de novo purine synthesis was calculated from the sum of radioactive purines in the cells and in the medium. Since the radioactive formate may not be incorporated equally into position 2 and 8 of the purine ring, the data are expressed as cpm per hour per $10^{6}$ cells instead of as picomoles per hour per $10^{6}$ cells. The assay was linear with time to $2 \mathrm{~h}$ and with cell density from 0.5 to $2 \times 10^{6} \mathrm{cells} / \mathrm{ml}$.

\section{Results}

Methionine and serine synthesis. When cells were exposed to $\mathrm{N}_{2} \mathrm{O}$, rates of methionine synthesis decreased rapidly by $52 \%$ after $30 \mathrm{~min}$ and $89 \%$ after $4 \mathrm{~h}$ (Fig. $2 \mathrm{~A}$ ). Rates of serine synthesis decreased after $\mathrm{N}_{2} \mathrm{O}$ exposure by $18 \%$ at $30 \mathrm{~min}$ and $49 \%$ at $4 \mathrm{~h}$ (Fig. $2 \mathrm{~B}$ ). The rapid and profound decrease in methionine synthesis after $\mathrm{N}_{2} \mathrm{O}$ exposure is compatible with the previously demonstrated rate of $\mathrm{N}_{2} \mathrm{O}$ inactivation of methionine synthetase (16). The more gradual decrease in serine synthesis after $\mathrm{N}_{2} \mathrm{O}$ exposure may also be secondary to methionine synthetase inhibition, if such inhibition leads to trapping of intracellular folates as 5-methyltetrahydrofolate (Fig. 1).

Purine synthesis at variable folate concentration. If methionine synthetase inhibition causes 5-methyltetrahydrofolate to accumulate at the expense of free tetrahydrofolate, then rates of purine synthesis should decrease in $\mathrm{N}_{2} \mathrm{O}$-treated cells (Fig. 1). In untreated control cells, rates of purine synthesis were independent of the folate concentration in the medium: only the data at $100 \mu \mathrm{M}$ folate are shown (Fig. 3, solid circles) but similar data were obtained at 1 or $10 \mu \mathrm{M}$ folate or in the absence of folate, indicating that for the duration of the experiments the intracellular folate stores were sufficient under control conditions. However, in $\mathrm{N}_{2} \mathrm{O}$-treated cells, rates of purine synthesis decreased with time and the rate of decrease was greater in the absence of folate. At 1, 10, 100, or 1,000 $\mu \mathrm{M}$ folate, $4 \mathrm{~h}$ of $\mathrm{N}_{2} \mathrm{O}$ exposure did not affect rates of purine synthesis appreciably, but after $14 \mathrm{~h}$ of exposure purine synthetic rates decreased by $25 \%(P<0.05, t$ test $)$; only the data at 100 $\mu \mathrm{M}$ folate are shown (Fig. 3, solid triangles). Similar data were obtained in the presence of 100 or $1,000 \mu \mathrm{M} 5$-formyltetrahydrofolate. In the absence of folate, $\mathrm{N}_{2} \mathrm{O}$ decreased rates of purine synthesis more rapidly-by $20 \%$ at $4 \mathrm{~h}(P<0.05, t$ 


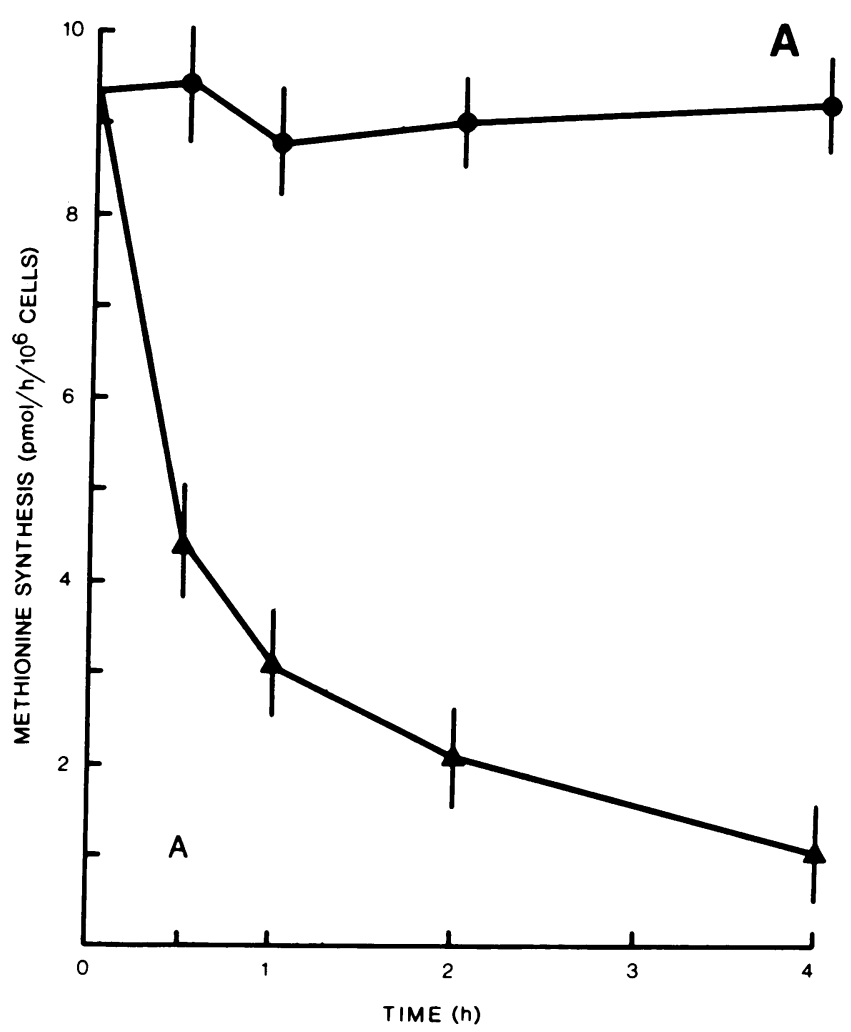

Figure 2. Rates of methionine $(A)$ and serine $(B)$ synthesis in cells incubated in the absence $(-\bullet-)$ or presence of $\mathrm{N}_{2} \mathrm{O}(-\Delta-)$. Cells were equilibrated in tubes for $10 \mathrm{~h}$ in $95 \%$ air $/ 5 \% \mathrm{CO}_{2}$; at zero time, half of the tubes were flushed with $75 \% \mathrm{~N}_{2} \mathrm{O} / 20 \% \mathrm{O}_{2} / 5 \% \mathrm{CO}_{2}$. Rates of methionine and serine synthesis were measured by following

test) (Fig. 3, solid squares). These data are further evidence that methionine synthetase inhibition decreases the availability of free tetrahydrofolate.

Purine synthesis at variable methionine concentration. To determine if the decrease in purine synthesis during methionine synthetase inhibition was secondary to methionine deprivation of the cell (17), rates of purine synthesis were measured in $\mathrm{N}_{2} \mathrm{O}$-treated cells over a range of methionine concentrations that included the normal plasma concentration of $6-30 \mu \mathrm{M}$ (20-22). In untreated control cells, rates of purine synthesis were dependent on the methionine concentration but were independent of the folate concentration; only the data at 100 $\mu \mathrm{M}$ folate are shown (Fig. 4, solid circles). The marked decrease in rates of purine synthesis at low methionine concentrations also occurs at low concentrations of any of the other essential amino acids; this is secondary to decreased phosphoribosylpyrophosphate production by the pentose phosphate pathway $(17,23,24)$. When cells were treated with $\mathrm{N}_{2} \mathrm{O}$, rates of purine synthesis decreased more in the absence of folate than in the presence of folate: only the data in the absence of folate and at $100 \mu \mathrm{M}$ folate are shown (Fig. 4, solid squares and solid triangles, respectively) with the data at 1 and $10 \mu \mathrm{M}$ folate similar to those at $100 \mu \mathrm{M}$ folate. $\mathrm{N}_{2} \mathrm{O}$ reduced rates of purine synthesis most efficiently at the physiologic methionine concentrations of 10 and $30 \mu \mathrm{M}$; thus, rates of purine synthesis at 30 and $10 \mu \mathrm{M}$ methionine were decreased

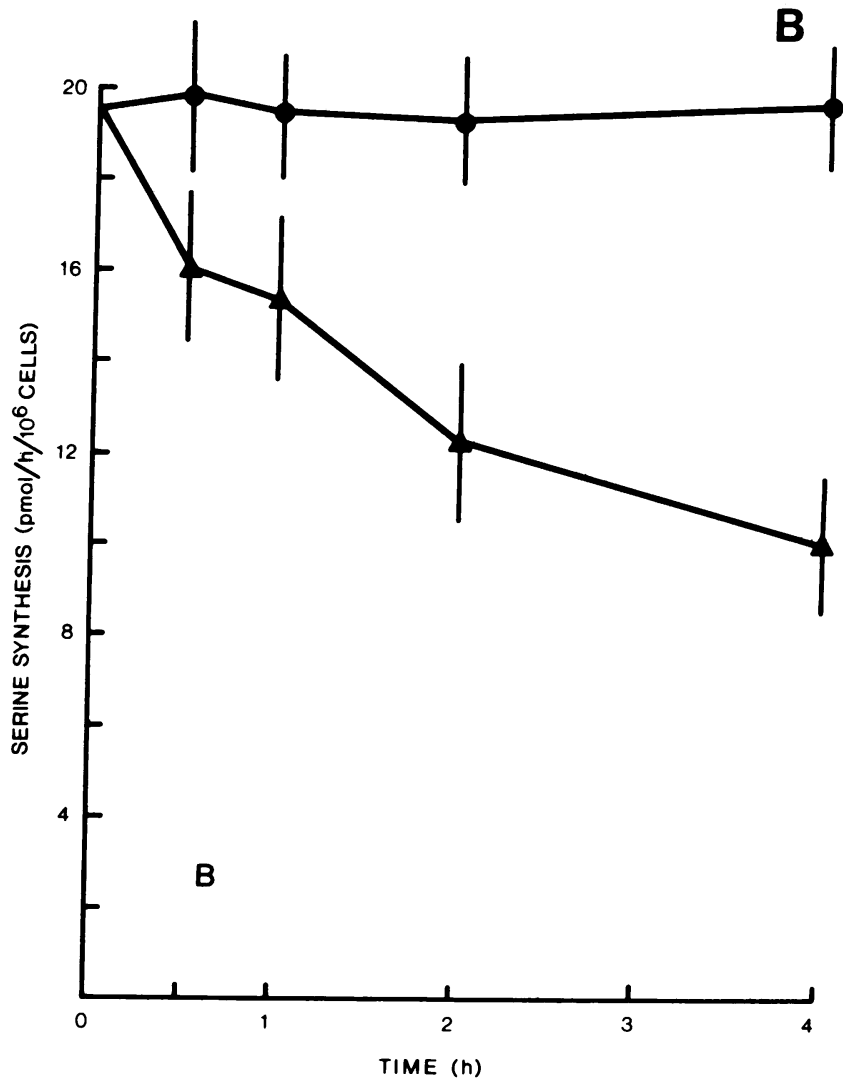

$\left[{ }^{14} \mathrm{C}\right]$ formate incorporation into methionine and serine residues of cellular protein as described fully in Methods. Each point is the mean $\pm \mathrm{SD}$ of at least three independent experiments performed in duplicate.

in the presence of $100 \mu \mathrm{M}$ folate by 22 and $33 \%$, respectively, and in the absence of folate by 37 and $57 \%$, respectively.

Purine synthesis in the presence of homocysteine. Since $\mathrm{N}_{2} \mathrm{O}$ inhibits methionine synthesis from homocysteine and rates of purine synthesis are reduced at low methionine concentrations, purine synthesis should decrease even more dramatically in $\mathrm{N}_{2} \mathrm{O}$-treated cells incubated in medium in which homocysteine replaces methionine. After $30 \mathrm{~min}$ and 4 $h$ of $\mathrm{N}_{2} \mathrm{O}$ exposure, rates of purine synthesis decreased by 56 and $75 \%$, respectively, when cells were incubated in methioninefree medium containing $200 \mu \mathrm{M}$ homocysteine thiolactone, $100 \mu \mathrm{M}$ folic acid, and $1.5 \mu \mathrm{M}$ cobalamin (Fig. 5). These experiments were performed only at a folate concentration of $100 \mu \mathrm{M}$ because cells cultured in the presence of homocysteine require relatively high concentrations of folate to synthesize purines and grow normally (data not shown) (25).

\section{Discussion}

Previous studies in rats have shown that $\mathrm{N}_{2} \mathrm{O}$ rapidly inhibits liver methionine synthetase activity by inactivating cobalamin (16). Since enzyme activity measured in cell extracts under nonphysiologic conditions does not always correlate with physiologic activity of the enzyme (26), we decided to measure rates of methionine synthesis in $\mathrm{N}_{2} \mathrm{O}$-treated cultured human lymphoblasts. We found that $\mathrm{N}_{2} \mathrm{O}$ rapidly decreased methionine synthesis from homocysteine. 


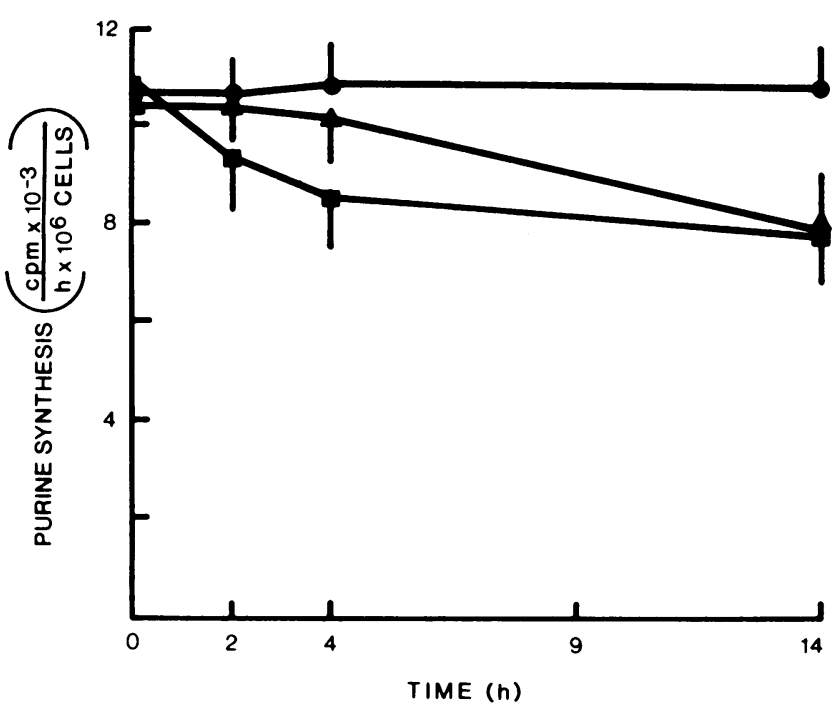

Figure 3. Rates of purine synthesis in cells incubated in the absence of $\mathrm{N}_{2} \mathrm{O}(-\bullet-)$ or in the presence of $\mathrm{N}_{2} \mathrm{O}$ at either $100 \mu \mathrm{M}$ folate $(-\triangle-)$ or in the absence of folate (- - Cells were incubated in either $95 \%$ air $/ 5 \% \mathrm{CO}_{2}$ or $75 \% \mathrm{~N}_{2} \mathrm{O} / 20 \% \mathrm{O}_{2} / 5 \% \mathrm{CO}_{2}$; at the indicated times, rates of purine synthesis were measured by following $\left[{ }^{14} \mathrm{C}\right]$ formate incorporation for $1 \mathrm{~h}$ into all intracellular and extracellular purines as described fully in Methods. Each point is the mean \pm SD of at least three independent experiments performed in duplicate.

Since 5-methyltetrahydrofolate appears to be the major storage form of intracellular folates and the reaction of 5,10methylenetetrahydrofolate reductase seems to be essentially irreversible in vivo, cobalamin deficiency may lead to 5methyltetrahydrofolate accumulation and a relative lack of other folate forms. We found that two pathways which require tetrahydrofolate derivatives, serine and purine de novo synthesis, were decreased in $\mathrm{N}_{2} \mathrm{O}$-treated cells, thus providing further

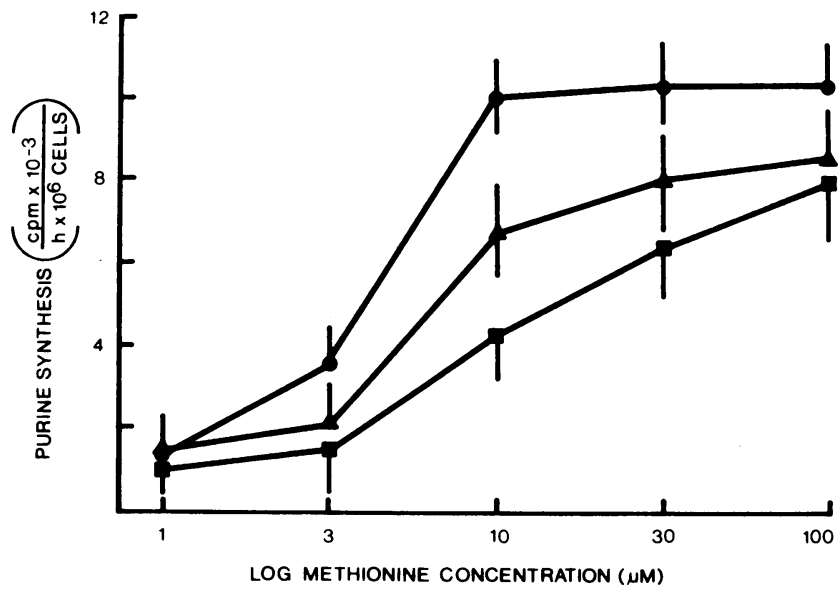

Figure 4. Rates of purine synthesis in cells incubated in the absence of $\mathrm{N}_{2} \mathrm{O}(-\bullet-)$ or in the presence of $\mathrm{N}_{2} \mathrm{O}$ at either $100 \mu \mathrm{M}$ folate $(-\triangle-)$ or in the absence of folate (- - Cells were incubated in either $95 \%$ air $/ 5 \% \mathrm{CO}_{2}$ or $75 \% \mathrm{~N}_{2} \mathrm{O} / 20 \% \mathrm{O}_{2} / 5 \% \mathrm{CO}_{2}$ at the indicated methionine concentrations; after $4 \mathrm{~h}$, rates of purine synthesis were measured as described in the legend to Fig. 3. Each point is the mean $\pm S D$ of at least three independent experiments performed in duplicate.

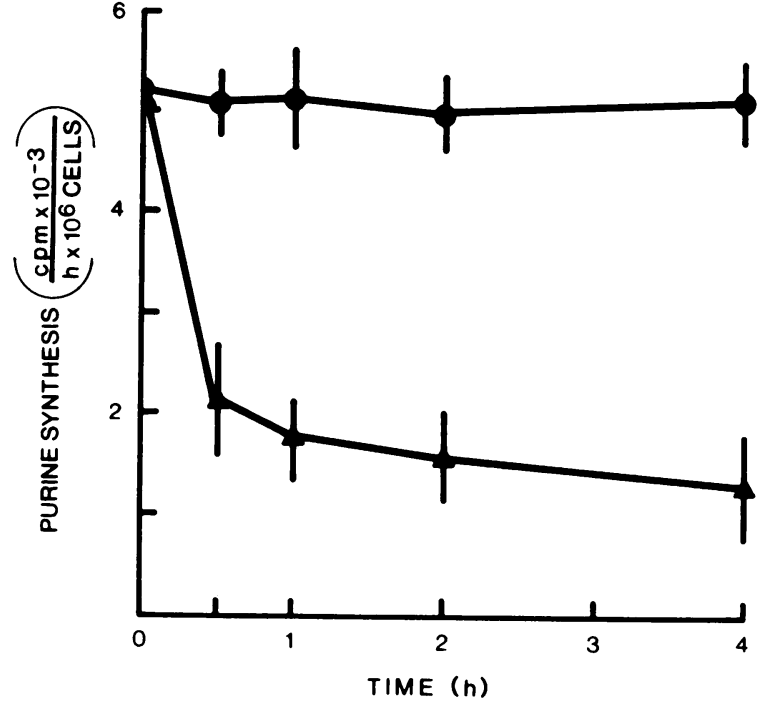

Figure 5. Rates of purine synthesis in cells incubated in the absence $(-\bullet-)$ or presence of $\mathrm{N}_{2} \mathrm{O}(-\wedge-)$. Cells were incubated in either 95\% air $/ 5 \% \mathrm{CO}_{2}$ or $75 \% \mathrm{~N}_{2} \mathrm{O} / 20 \% \mathrm{O}_{2} / 5 \% \mathrm{CO}_{2}$ in medium lacking methionine but containing $200 \mu \mathrm{M}$ homocysteine thiolactone; after 4 $h$, rates of purine synthesis were measured as described in the legend to Fig. 3. Each point is the mean $\pm S D$ of at least three independent experiments performed in duplicate.

evidence that supports the methylfolate trap hypothesis. However, the considerably less pronounced decrease in rates of serine and purine synthesis compared with methionine synthesis suggest that the trap is incomplete. Furthermore, if 5-methyltetrahydrofolate trapping were the only sequelae of cobalamin inactivation, other folate forms should return rates of purine synthesis towards control values in $\mathrm{N}_{2} \mathrm{O}$-treated cells. We found that neither folic acid nor 5-formyltetrahydrofolate in concentrations as high as $1 \mathrm{mM}$ fully reversed the $\mathrm{N}_{2} \mathrm{O}$ effect on purine synthesis. Thus, our data suggest that cobalamin inactivation decreases purine synthesis by an additional mechanism which is independent of 5-methyltetrahydrofolate trapping.

This additional mechanism appears to be reduced methionine synthesis. At physiologic methionine concentrations, i.e., 6-30 $\mu \mathrm{M}$, rates of purine synthesis were more profoundly inhibited by $\mathrm{N}_{2} \mathrm{O}$ than at the standard tissue culture medium concentration of $100 \mu \mathrm{M}$. Moreover, rates of purine synthesis were markedly inhibited by $\mathrm{N}_{2} \mathrm{O}$ when homocysteine replaced methionine in the culture medium. Thus, when the cell is relatively limited for methionine, inhibition of methionine synthetase has a more pronounced effect than when ample methionine is present. This suggests that a significant proportion of cellular methionine is normally converted to homocysteine, via $S$-adenosylmethionine and $S$-adenosylhomocysteine (Fig. 1 ), and regenerated by methionine synthetase. Similar conclusions were reached recently by German et al. (27), who found in cultured lymphoblasts that $\sim 20 \%$ of intracellular methionine traverses this cycle at any time; and by Finkelstein and Martin (28), who found in an in vitro system which simulates the in vivo conditions of rat liver, that methionine synthetase activity accounted for $27 \%$ of the homocysteine consumed. This relatively high rate of homocysteine production from methionine does not account for the greater rate of purine synthesis 
at high methionine concentrations in $\mathrm{N}_{2} \mathrm{O}$-treated cells, because, even in the presence of $200 \mu \mathrm{M}$ homocysteine thiolactone, rates of purine synthesis were markedly reduced by $\mathrm{N}_{2} \mathrm{O}$.

Limiting the cell's ability to synthesize methionine, and thus decreasing intracellular methionine availability, could decrease purine synthesis by at least three different mechanisms. First, decreased methionine synthesis and availability may lead to decreased $S$-adenosylmethionine synthesis (Fig. 1). $S$-adenosylmethionine is a potent inhibitor of 5,10-methylenetetrahydrofolate reductase (29); a decrease in the intracellular $S$ adenosylmethionine concentration could increase 5,10-methylenetetrahydrofolate conversion to 5-methyltetrahydrofolate, thus exacerbating the methylfolate trap (Fig. 1) (7). Moreover, $S$-adenosylmethionine is the main intracellular methyl donor and a decrease in its concentration could have profound effects on many enzymatic reactions (30). Second, Perry and Chanarin $(15,31-33)$ suggested that methionine may be a major provider of cellular formate and thereby may serve as a precursor of the purine ring. They showed that folate polyglutamate synthesis with tetrahydrofolate as the substrate is markedly impaired in the $\mathrm{N}_{2} \mathrm{O}$-treated rat but is normal when formyltetrahydrofolate is the substrate. The ability to use tetrahydrofolate can be restored when either methionine, $S$-adenosylmethionine, or 5'methylthioadenosine are infused (15). All three of these compounds are potential sources of 1-phospho-5-methylthioribose, which has been shown recently to be metabolized to formate and 2-keto-4-methylthiobutyrate (34). In addition, the methyl group of methionine may be oxidized intracellularly to formate (35). And third, decreased methionine availability decreases the synthesis of phosphoribosylpyrophosphate, which is the first and a key regulatory substrate of de novo purine synthesis (24). We have shown that when cultured human lymphoblasts are starved for an essential amino acid for brief periods of time, rates of de novo purine synthesis decrease by as much as $90 \%$ (17). This rapid decrease in purine nucleotide synthesis is mostly secondary to decreased phosphoribosylpyrophosphate synthesis by the nonoxidative pentose phosphate pathway $(23$, $24,36)$.

There is clinical evidence for reduced methionine synthesis and a state of partial methionine deprivation in cobalamin deficiency since (a) cobalamin deficiency may be associated with homocystinuria (37-39); and (b) methionine administration to cobalamin-deficient patients decreases the excretion of formiminoglutamic acid, a marker of cobalamin deficiency (40).

\section{Acknowledgments}

I would like to thank Dr. Richard W. Erbe for his support as this work was initiated in his laboratory in the Genetics Unit of the Massachusetts General Hospital, Boston, MA. I appreciate the skillful technical assistance of Ms. Susan Sweeney and the excellent preparation of the manuscript by Mrs. Debbie Lundemo and Ms. Jean Grigsby.

This work was supported in part by a Cancer Coordinating Research Committee Award of the University of California. Dr. Boss is the recipient of a U. S. Public Health Service New Investigator Award AG 03156 and is a Henry J. Kaiser Family Foundation Scholar in General Internal Medicine.

\section{References}

1. Weissbach, H., and H. Dickerman. 1965. Biochemical role of vitamin $\mathrm{B}_{12}$. Physiol. Rev. 45:80-98.
2. Beck, W. S. 1975. Metabolic features of cobalamin deficiency in man. In Cobalamin. B. M. Babior, editor. John Wiley \& Sons, Inc., New York. First ed. 403-450.

3. Frenkel, E. P. 1973. Abnormal fatty acid metabolism in peripheral nerves of patients with pernicious anemia. J. Clin. Invest. 52:12371245.

4. Rosenblatt, D. S., B. A. Cooper, S. Lue-Shing, P. W. K. Wong, S. Berlow, K. Narisawa, and R. Baumgartner. 1979. Folate distribution in cultured human cells. Studies on $5,10-\mathrm{CH}_{2}-\mathrm{H}_{4}$ PTEGLU reductase deficiency. J. Clin. Invest. 63:1019-1025.

5. Erbe, R. W. 1979. Genetic aspects of folate metabolism. Adv. Hum. Genet. 9:293-354.

6. Nixon, P. F., and J. R. Bertino. 1970. Interrelationships of vitamin $\mathrm{B}_{12}$ and folate in man. Am. J. Med. 48:555-561.

7. Herbert, V., and C. D. Kshitish. 1976. The role of vitamin $B_{12}$ and folic acid in hemato- and other cell-poiesis. Vitam. Horm. 34:1-30.

8. Taheri, M. R., R. G. Wickremasinghe, B. F. A. Jackson, and A. V. Hoffbrand. 1982. The effect of folate analogues and vitamin $B_{12}$ on provision of thymine nucleotides for DNA synthesis in megaloblastic anemia. Blood. 59:634-640.

9. Marshall, R. A., and J. H. Jandl. 1960. Responses to "physiologic" doses of folic acid in the megaloblastic anemias. Arch Int. Med. 105: 352-361.

10. Deacon, R., I. Chanarin, J. Perry, and M. Lumb. 1980. Marrow cell from patients with untreated pernicious anaemia cannot use tetrahydrofolate normally. Br. J. Haematol. 46:523-528.

11. Lumb, M., R. Deacon, J. Perry, I. Chanarin, B. Minty, M. J. Halsey, and J. F. Nunn. 1980. The effect of nitrous oxide inactivation of vitamin $B_{12}$ on rat hepatic folate. Implications for the methylfolatetrap hypothesis. Biochem. J. 186:933-936.

12. Lumb, M., J. Perry, R. Deacon, and I. Chanarin. 1981. Changes in tissue folates accompanying nitrous oxide-induced inactivation of vitamin $\mathrm{B}_{12}$ in the rat. Am. J. Clin. Nutr. 34:2412-2417.

13. Amess, J. A. L., J. F. Burman, G. M. Rees, D. G. Nancekievill, and D. L. Mollin. 1978. Megaloblastic haemopoiesis in patients receiving nitrous oxide. Lancet. II:339-342.

14. Lassen, H. C. A., E. Henriksen, F. Neukirch, and H. S. Kristensen. 1956. Treatment of tetanus. Severe bone-marrow depression after prolonged nitrous-oxide anaesthesia. Lancet. I:527-530.

15. Perry, J., I. Chanarin, R. Deacon, and M. Lumb. 1983. Chronic cobalamin inactivation impairs folate polyglutamate synthesis in the rat. J. Clin. Invest. 71:1183-1190.

16. Kondo, H., M. L. Osborne, J. F. Kolhouse, M. J. Binder, E. R. Podell, C. S. Utley, R. S. Abrams, and R. H. Allen. 1981. Nitrous oxide has multiple deleterious effects on cobalamin metabolism and causes decreases in activities of both mammalian cobalamindependent enzymes in rats. J. Clin. Invest. 67:1270-1283.

17. Boss, G. R., and R. W. Erbe. 1982. Decreased purine synthesis during amino acid starvation of human lymphoblasts. J. Biol. Chem. 257:4242-4247.

18. Boss, G. R., and R. W. Erbe. 1981. Decreased rates of methionine synthesis by methylene tetrahydrofolate reductase-deficient fibroblasts and lymphoblasts. J. Clin. Invest. 67:1659-1664.

19. Boss, G. R., and R. B. Pilz. 1984. Decreased methionine synthesis in purine nucleoside-treated $\mathrm{T}$ and $\mathrm{B}$ lymphoblasts and reversal by homocysteine. J. Clin. Invest. 74:1262-1268.

20. Perry, T. L., D. L. Love, S. Hansen, L. E. Crawford, and B. Tischler. 1968. Treatment of homocystinuria with low-methionine diet, supplemental cystine, and a methyl donor. Lancet. I:474-478.

21. Perry, T. L., S. Hansen, L. MacDougall, and P. D. Warrington. 1967. Sulfur-containing amino acids in the plasma and urine of homocystinurics. Clin. Chim. Acta. 15:409-420.

22. Schuh, S., D. S. Rosenblatt, B. A. Cooper, M. Schroeder, A. J. Bishop, L. E. Seargeant, and J. C. Haworth. 1984. Homocystinuria and megaloblastic anemia responsive to vitamin $B_{12}$ therapy. An inborn error of metabolism due to a defect in cobalamin metabolism. N. Engl. J. Med. 310:686-690. 
23. Pilz, R. B., R. C. Willis, and G. R. Boss. 1984. The influence of ribose 5-phosphate availability on purine synthesis of cultured human lymphoblasts and mitogen-stimulated lymphocytes. J. Biol. Chem. 259:2927-2935.

24. Boss, G. R. 1984. Decreased phosphoribosylpyrophosphate as the basis for decreased purine synthesis during amino acid starvation of human lymphoblasts. J. Biol. Chem. 259:2936-2941.

25. Rosenblatt, D. S., and R. W. Erbe. 1977. Methylenetetrahydrofolate reductase in cultured human cells. I. Growth and metabolic studies. Pediatr. Res. 11:1137-1141.

26. Yoshida, A. 1979. Hemolytic anemia and G6PD deficiency. Science (Wash. DC). 179:532-537.

27. German, D. C., C. A. Bloch, and N. M. Kredich. 1983 Measurements of $S$-adenosylmethionine and L-homocysteine metabolism in cultured human lymphoid cells. J. Biol. Chem. 258:1099711003.

28. Finkelstein, J. D., and J. J. Martin. 1984. Methionine metabolism in mammals. Distribution of homocysteine between competing pathways. J. Biol. Chem. 259:9508-9513.

29. Kutzbach, C., and E. L. R. Stokstad. 1971. Mammalian methylenetetrahydrofolate reductase. Partial purification, properties, and inhibition by $S$-adenosylmethionine. Biochim. Biophys. Acta. 250: 459-477.

30. Lombardini, J. B., and P. Talalay. 1971. Formation, functions and regulatory importance of S-adenosyl-L-methionine. Adv. Enzyme Regulation. 9:349-384.

31. Perry, J., I. Chanarin, R. Deacon, and M. Lumb. 1979. The substrate for folate polyglutamate biosynthesis in the vitamin $B_{12^{-}}$ inactivated rat. Biochem. Biophys. Res. Commun. 91:678-684.

32. Deacon, R., I. Chanarin, J. Perry, and M. Lumb. 1980.
Impaired deoxyuridine utilization in the $B_{12}$-inactivated rat and its correction by folate analogues. Biochem. Biophys. Res. Commun. 93: 516-520.

33. Lumb, M., R. Deacon, J. Perry, I. Chanarin, B. Minty, M. J. Halsey, and J. F. Nunn. 1980. The effect of nitrous oxide inactivation of vitamin $B_{12}$ on rat hepatic folate. Implications for the methylfolatetrap hypothesis. Biochem. J. 186:933-936.

34. Backlund, P. S., Jr., C. P. Chang, and R. A. Smith. 1982. Identification of 2-keto-4-methylthiobutyrate as an intermediate compound in methionine synthesis from 5 '-methylthioadenosine. J. Biol. Chem. 257:4196-4202.

35. Siekevitz, P., and D. M. Greenberg. 1950. The biological formation of formate from methyl compounds in liver slices. J. Biol. Chem. 186:275-286.

36. Boss, G. R., and R. B. Pilz. Phosphoribosylpyrophosphate synthesis from glucose decreases during amino acid starvation of human lymphoblasts. J. Biol. Chem. In press.

37. Shipman, R. T., R. R. W. Townley, and D. M. Danks. 1969. Homocystinuria, Addisonian pernicious anemia, and partial deletion of a G chromosome. Lancet. II:693-695.

38. Hollowell, J. G., Jr., W. K. Hall, M. E. Coryell, J. McPherson, Jr., and D. A. Hahn. 1969. Homocystinuria and organic aciduria in a patient with vitamin-B $B_{12}$ deficiency. Lancet. II:1428-1430.

39. Higginbottom, M. C., L. Sweetman, and W. L. Nyhan. 1978. A syndrome of methylmalonic aciduria, homocystinuria, megaloblastic anemia and neurologic abnormalities in a vitamin $B_{12}$-deficient breastfed infant of a strict vegetarian. N. Engl. J. Med. 299:317-325.

40. Herbert, V., and L. W. Sullivan. 1963. Formiminoglutamic aciduria in humans with megaloblastic anemia: diminution by methionine or glycine. Proc. Soc. Exp. Biol. Med. 112:304-311. 